\title{
ON THE MATRIX WHICH IS THE SUM OF A TRIPOTENT AND A QUASINILPOTENT MATRICES
}

\section{HuAnyin Chen And MARJAn Sheibani AbDolyousefi}

Abstract. We investigate Hirano polar matrices over a local ring, and completely determine when a $2 \times 2$ matrix over a local ring is the sum of a tripotent and a quasinilpotent matrix.

Mathematics subject classification (2010): 15A09, 32A65, 16E50.

Keywords and phrases: Tripotent, quasinilpotent, Jacobson radical, $2 \times 2$ matrix, local ring.

\section{REFERENCES}

[1] H. CHen, On strongly nil clean matrices, Comm. Algebra, 41(2013), 1074-1086.

[2] H. Chen And M. Sheibani, Strongly 2-nil-clean rings, J. Algebra Appl., 16(2017) 1750178 (12 pages), DOI: 10.1142/S021949881750178X.

[3] J. Chen, X. YANG AND Y. ZHOU, When is the $2 \times 2$ matrix ring over a commutative local ring strongly clean?, J. Algebra, 301(2006), 280-293.

[4] J. CUI AND J. CHEN, When is a $2 \times 2$ matrix ring over a commutative local ring quasipolar? Comm. Algebra, 39(2011), 3212-3221.

[5] J. Cui AND J. Chen, A class of quasipolar rings, Comm. Algebra, 40(2012), 4471-4482.

[6] J. CUI AND J. Chen, Quasipolar matrix rings over local rings, Bull. Korean Math. Soc., 51(2014), $813-822$.

[7] J. Cui And J. Chen, Pseudopolar matrix rings over local rings, J. Algebra Appl., 13(2014), 1350109 [12 pages], DOI: 10.1142/S0219498813501090.

[8] O. GURGUn, Properties of generalized strongly Drazin invertible elements in general rings, J. Algebra Appl., 16, 1750207 (2017) [13 pages], DOI: 10.1142/S0219498817502073.

[9] R. HARTE, Invertibility and singularity for bounded linear operators, Monographs and Textbooks in Pure and Applied Mathematics, 109, Marcel Dekker, Inc., New York, 1988.

[10] A. Karimi-Mansoub, T. Kos An AND Y. Zhou, Rings in which every unit is a sum of a nilpotent and an idempotent, arXiv: 1710.025557v1, [math.RA] 6 Oct 2017.

[11] M. T. KosAn, Z. WANG AND Y. ZHOU, Nil-clean and strongly nil-clean rings, J. Pure Appl. Algebra (2015), http://dx.doi.org/10.1016/j.jpaa.2015.07. 009.

[12] B. LI, Strongly clean matrix rings over noncommutative local rings, Bull. Korean Math. Soc., 46(2009), 71-78.

[13] Z. WANG, A class of Drazin inverses in rings, Filomat, 31(2017), 1781-1789.

[14] X. YAng AND Y. Zhou, Strong cleanness of the $2 \times 2$ matrix ring over a general local ring, J. Algebra, 320(2008), 2280-2290.

[15] Z. L. Ying, T. KosAN AND Y. ZHOU, Rings in which every element is a sum of two tripotents, Canad. Math. Bull., http://dx.doi.org/10.4153/CMB-2016-009-0. 